\title{
Metformin and SARS-CoV-2: mechanistic lessons on air pollution to weather the cytokine/thrombotic storm in COVID-19
}

\author{
Javier A. Menendez ${ }^{1,2}$ \\ ${ }^{1}$ Program Against Cancer Therapeutic Resistance (ProCURE), Metabolism and Cancer Group, Catalan Institute of \\ Oncology, Girona, Spain \\ ${ }^{2}$ Girona Biomedical Research Institute (IDIBGI), Girona, Spain
}

Correspondence to: Javier A. Menendez; email: jmenendez@idibgi.org Keywords: air pollution, particulate matter, inflammation, aging, COVID-19

Received: April 29, 2020

Accepted: May 19, 2020

Published: May 27, 2020

Copyright: Menendez. This is an open-access article distributed under the terms of the Creative Commons Attribution License (CC BY 3.0), which permits unrestricted use, distribution, and reproduction in any medium, provided the original author and source are credited.

\section{ABSTRACT}

Pathological signaling in the lung induced by particulate matter (PM) air pollution partially overlaps with that provoked by COVID-19, the pandemic disease caused by infection with the novel coronavirus SARS-CoV-2. Metformin is capable of suppressing one of the molecular triggers of the proinflammatory and prothrombotic processes of urban PM air pollution, namely the mitochondrial $\mathrm{ROS} / \mathrm{Ca}^{2+}$ release-activated $\mathrm{Ca}^{2+}$ channels (CRAC)/IL-6 cascade. Given the linkage between mitochondrial functionality, ion channels, and inflamm-aging, the ability of metformin to target mitochondrial electron transport and prevent ROS/CRAC-mediated IL-6 release might illuminate new therapeutic avenues to quell the raging of the cytokine and thrombotic-like storms that are the leading causes of COVID-19 morbidity and mortality in older people. The incorporation of infection rates, severity and lethality of SARS-CoV-2 infections as new outcomes of metformin usage in elderly populations at risk of developing severe COVID-19, together with the assessment of bronchial/serological titers of inflammatory cytokines and D-dimers, could provide a novel mechanistic basis for the consideration of metformin as a therapeutic strategy against the inflammatory and thrombotic states underlying the gerolavic traits of SARS-CoV-2 infection.

Particulate matter air pollution and SARS-CoV2/COVID-19: A mechanistically linked pathway illuminating a therapeutic opportunity for metformin

Particulate matter (PM) air pollution concentrations frequently encountered in major cities can trigger the release of proinflammatory interleukins (e.g., IL-6) from alveolar macrophages, promoting an acceleration of arterial thrombosis [1]. Analogously, infection with the novel SARS-CoV-2 coronavirus can stimulate a too-littletoo-late type-I interferon-mediated innate immune response, which is inherently accompanied by dysregulated secretion of IL-6 from alveolar macrophages $[2,3]$. The so-called cytokine storm - involving overproduction of proinflammatory cytokines and overactivation of immune cells (hyperinflammation) ultimately drives an acute respiratory distress syndrome
(ARDS), one of the leading causes of mortality in patients with severe COVID-19 disease [4, 5]. Intriguingly, patients with severe COVID-19 admitted to the intensive care unit are at highest thrombotic risk, with acute pulmonary embolism being the most common thrombotic complication [6]. The ability of COVID-19 to predispose to thromboembolism, which can fuel futile cycles of hyperinflammatory responses that aggravate SARS-CoV2 pathogenesis [7,8], is increasingly viewed as a major factor in disease severity and mortality. It is thus not surprising that long-term exposure to $\mathrm{PM}$ has been recently proposed as a key contributor to COVID-19 mortality in the United States [9]. Likewise, the elevated levels of PM air pollution in Northern Italy and central Spain have been postulated as a putative risk factor underlying the extremely high COVID-19 fatality rates observed in these European regions [10-12]. 
The link between air pollution and COVID-19 severity can be viewed merely as the passive result of a carrier action of virus particles by PM; yet, one should acknowledge that PM air pollution is also a principal cause of chronic systemic and airway inflammation, ultimately leading to innate immune system hyperactivation, elevated production of proinflammatory cytokines, and thrombosis [1, 10, 13-16]. The physiopathological overlap between PM-driven inflammatory cytokine production and the cytokine/thrombotic storm in patients with COVID-19 might also suggest a boosting action of the former on the SARS-CoV-2 mechanism of disease (Figure 1). Therapeutically, if the chronic pulmonary effects of PM impact the prognosis of COVID-19, it then follows that small molecules with acceptable risk profiles that can block the molecular trigger(s) of IL-6 release from alveolar macrophages in response to $\mathrm{PM}$ might also mitigate the aggressive proinflammatory/prothrombotic nature of COVID-19. Using sophisticated cell and mouse models, a groundbreaking study by the Budinger group established that the anti-diabetic drug metformin - through its capacity to inhibit mitochondrial complex I - suppressed the mitochondrial reactive oxygen species (ROS) signaling necessary for the opening of $\mathrm{Ca}^{2+}$ releaseactivated $\mathrm{Ca}^{2+}$ (CRAC) channels in the generation of IL6 from alveolar macrophages upon exposure to PM (Figure 2) [1]. Because the use a respiratory filter in people residing in areas with high levels of PM air pollution validated the causal link between PM
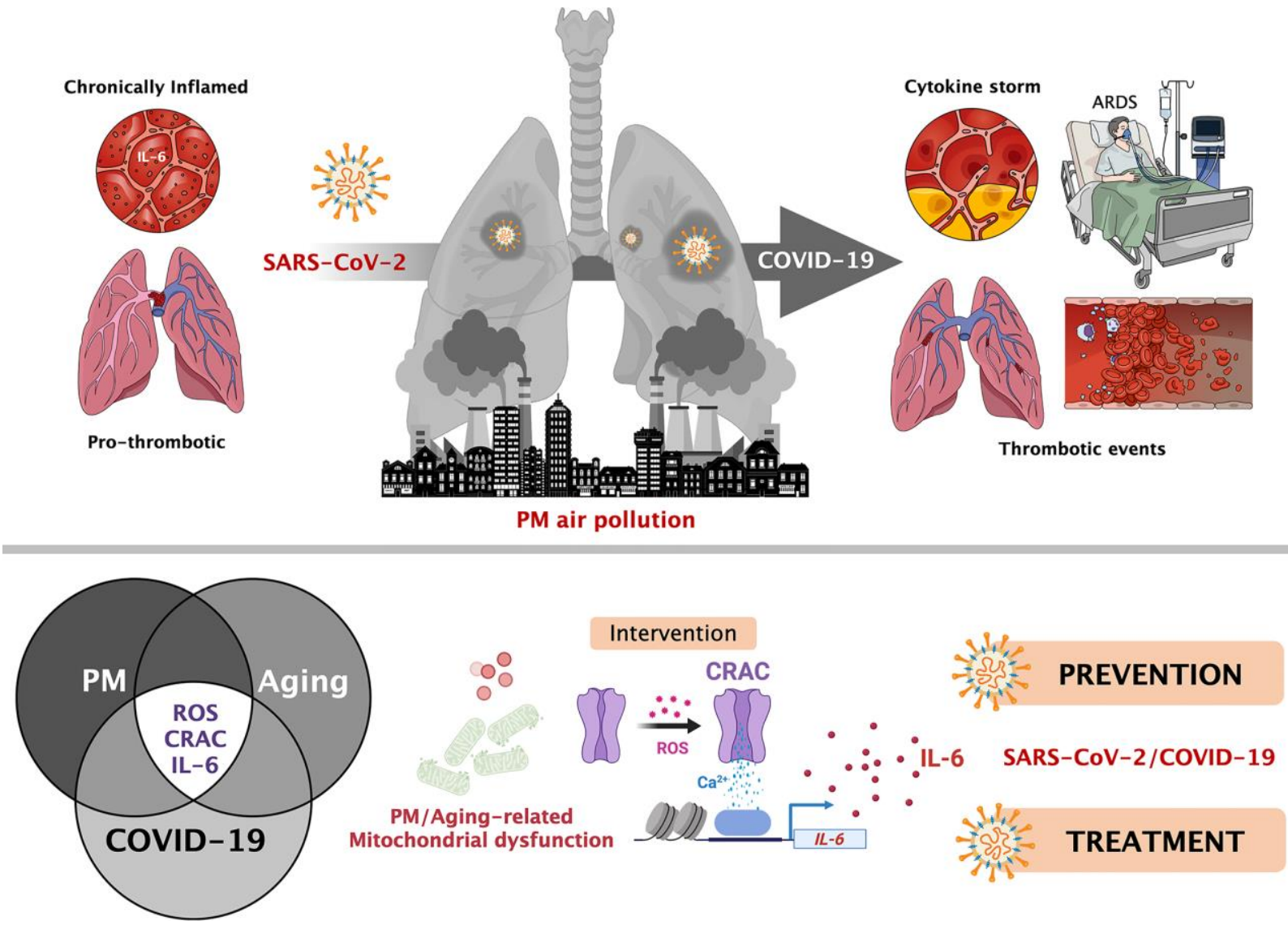

Figure 1. Particulate matter air pollution and SARS-CoV-2/COVID-19: A mechanistically linked pathway illuminating a therapeutic opportunity for metformin. Top. Pathological signaling in the lung induced by particulate matter (PM) air pollution partially overlaps with that caused by severe SARS-CoV-2/COVID-19, namely the release of proinflammatory interleukins (e.g., IL-6) from alveolar macrophages via mitochondrial reactive oxygen species (ROS)-driven activation of $\mathrm{Ca}^{2+}$ release-activated $\mathrm{Ca}^{2+}$ (CRAC) channels, lastly promoting an acceleration of thrombotic events. Patients already experiencing a chronic cytokine response might be at higher risk of COVID-19 lethal complications after SARS-CoV-2 infection. Bottom. Given the linkage between mitochondrial functionality, ion channels, and inflammation in human aging, therapeutic interventions capable of targeting mitochondrial electron transport and prevent mitochondrial ROS/CRAC-mediated IL-6 release (e.g., metformin) might illuminate a preventive/prophylactic mechanism of action to quell the raging of the cytokine and thrombotic-like storms that are the leading causes of COVID-19 morbidity and mortality in older people. In an acute scenario of SARS-CoV-2-driven hyperinflammation, small molecule CRAC channel inhibitors may also be contemplated as a means of treating patients with severe COVID-19 at risk for progressing to typical/atypical ARDS. 
exposure and levels of IL-6-related systemic markers [17], these findings altogether support metformin use as a preventive strategy for the mortality attributable to PM air pollution worldwide [1]. In the same line, it would be relevant to test whether metformin could suppress the cytokine and thrombotic-like storms in COVID-19 before they begin, thereby lowering the risk of severe disease in high-risk individuals.

ROS/CRAC/IL-6-targeted activity of metformin: From preventive therapy of the premature death attributable to PM air pollution to geroprotector against the gerophilic and gerolavic traits of SARSCoV-2 infection

Severe COVID-19 illness and death is more common in people aged 60 and older with underlying conditions, which can include chronic respiratory system disease not only due to chronic exposure to PM air pollution but also to immuno-senescence and inflamm-aging phenomena [18-22]. Given the linkage between mitochondria functionality, ion channels including CRAC, and inflamm-aging [23], the ability of metformin to target mitochondrial electron transport and prevent ROS/CRACmediated IL-6 release might illuminate a preventive (and prophylactic) measure to quell the raging of the cytokine and thrombotic-like storms that are the leading causes of COVID-19 morbidity and mortality in older people. Such CRAC-related mechanism of action [24] capable of preventing systemically IL-6-driven thrombotic events [1], together with the multi-faceted capacity of metformin to ameliorate immunometabolism-related inflammation and alleviate ARDS [25-27] - which are believed to be the main risk factors for a worse outcome in the elderly with COVID-19 [28, 29]- could provide a novel mechanistic basis for the recently proposed geroprotective role of metformin against the gerophilic and gerolavic traits of SARS-CoV-2 infection [30].

Previous randomized clinical trials and numerous retrospective observational studies have consistently associated metformin administration with significant improvement in risk factors of aging-related diseases (cardiovascular, neurodegenerative, and cancer) beyond type 2 diabetes [31-33]. Research is now urgently needed to test whether metformin might additionally
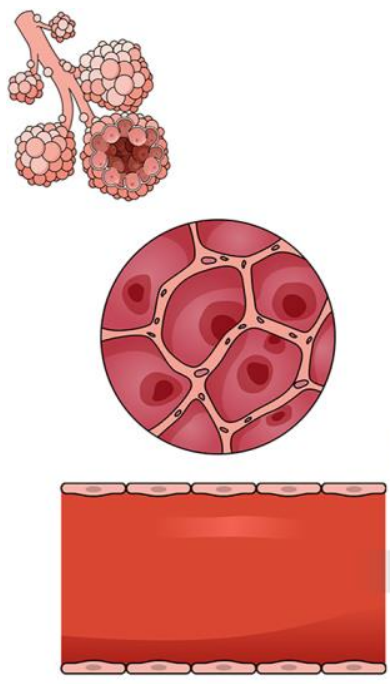<smiles>CN(C)C(=N)NC(=N)N</smiles>

$\perp$

ROS

CRAC

IL-6
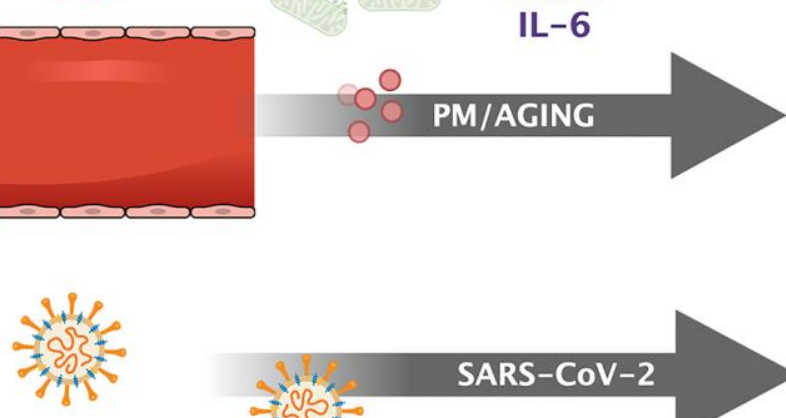

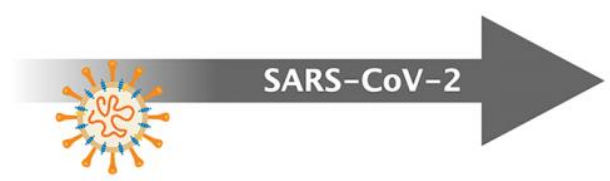

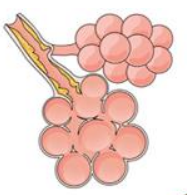

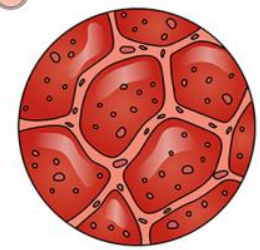

Chronically Inflamed

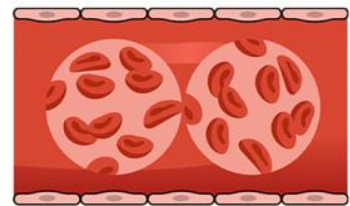

Pro-thrombotic
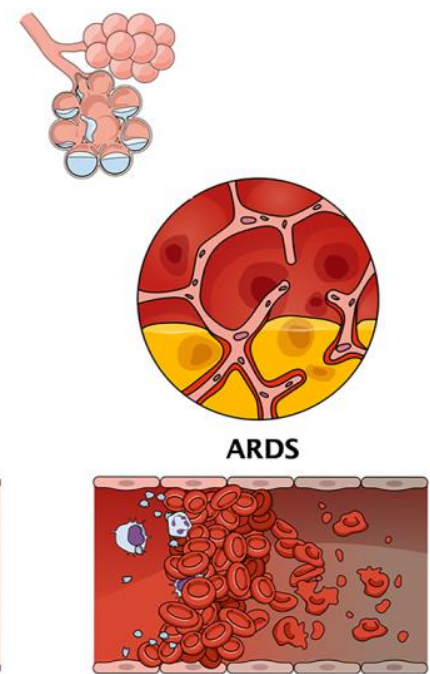

Thromboembolisms

Figure 2. CRAC-targeted activity of metformin: From preventive therapy of the premature death attributable to PM air pollution to geroprotector against the gerophilic and gerolavic traits of SARS-CoV-2 infection. The ability of metformin to suppress the signaling by mitochondrial reactive oxygen species (ROS) that are necessary for the opening of $\mathrm{Ca}^{2+}$ release-activated $\mathrm{Ca}^{2+}$ channels in the generation of IL- 6 from alveolar macrophages upon exposure to PM air pollution might mechanistically extend to the immune dysregulation/inflammation and thrombotic events driven by the systemic release of IL- 6 from lung macrophages in response to SARS-CoV-2 infection. By restraining the raging of cytokine and thrombotic-like storms, two of the leading causes of morbidity and mortality in SARS-CoV-2 infection, metformin might be considered a putative geroprotector against the gerophilic and gerolavic traits of COVID-19 disease. 
reduce the comorbidity, infection rate, severity, and lethality of SARS-CoV-2 infection, with special emphasis on the elderly risk groups accounting for the majority of severe COVID-19 disease and fatalities to date. Clinical trial strategies such as the TAME (Targeting Aging with Metformin) study, which plans to enroll 3,000 older subjects (ages 65-79) without type 2 diabetes who will be randomly assigned to $1,500 \mathrm{mg}$ metformin daily or placebo for 4 years to measure time to a new occurrence of a composite outcome that includes cardiovascular events, cancer, dementia, and mortality [31,33], provides an ideal opportunity to explore the recently proposed strategy of metformin as a low-cost geroprotector for prevention of SARS-CoV-2 [30]. In the meanwhile, observational studies in residential care nursing homes and day-care centers where older adults at significant risk of COVID-19 outbreaks are receiving metformin for treatment of type 2 diabetes (along with the assessment of bronchial/serological levels of inflammatory cytokines and markers of pro-thrombotic/hypercoagulable states such as D-dimers) might provide a deeper comprehension of how metformin can protect and potentiate common preventive strategies such as distancing measures, maskwearing, and hand-washing.

\section{CRAC channels and treatment of typical/atypical ARDS in severe COVID-19}

Targeting hyperinflammation in severe COVID-19 patients may be critical for reducing mortality. One might therefore wonder whether treatment with indirect (e.g., metformin [1]) or direct (e.g., CM4620 [34]) small-molecule inhibitors of CRAC channels could improve clinical outcomes in hospitalized patients with moderate/severe COVID-19. CM4620-IE, a potent and selective small molecule CRAC channel inhibitor that prevents channel overactivation and has demonstrated efficacy in patients with hypoxemia secondary to systemic inflammatory response syndrome in acute pancreatitis [34], will be trialed in patients with severe COVID-19 pneumonia at risk for progressing to ARDS (ClinicalTrials.gov identifier: NCT04345614). Because a subset of severe COVID-19 infections have a delayed onset of respiratory distress despite the severity of hypoxemia that clearly differs from classic ARDS but principally involves a catastrophic microvascular injury and thrombosis [35-37], it might be relevant to carefully evaluate the impact of targeting the mitochondrial ROS/CRAC/IL-6 signaling cascade in the respiratory, inflammatory, and survival outcomes during the "typical" and "atypical" presentation of ARDS in COVID-19 patients. Nonetheless, the findings from the clinical testing of CRAC-targeting drugs might link, at a mechanistic level, the metformin lessons on air pollution to ride (out) the cytokine/thrombotic storm in severe SARS-CoV-2/COVID-19.

\section{DISCLAIMER AND LIMITATIONS}

This perspective merely aims to stimulate new ideas as part of the global efforts aimed to develop new preventive/treatment strategies against the SARS-CoV2/COVID-19 outbreak. Accordingly, this perspective does not represent medical advice or therapeutic recommendations to either COVID-19 patients or people at risk of SARS-CoV-2 infection.

\section{ACKNOWLEDGMENTS}

This manuscript was written over the course of the second month of lockdown in Spain due to the SARSCoV-2 coronavirus pandemic in March-May 2020. This paper is dedicated to the memory of all those who have succumbed to COVID-19 during those hard days. The author would like to thank Dr. Kenneth McCreath for editorial support.

\section{CONFLICTS OF INTEREST}

The author declares no conflicts of interest.

\section{FUNDING}

No funding was received for the writing of this perspective. Work in the Menendez laboratory is supported by the Spanish Ministry of Science and Innovation (Grant SAF2016-80639-P, Plan Nacional de I+D+I, founded by the European Regional Development Fund, Spain) and by an unrestricted research grant from the Fundació Oncolliga Girona (Lliga catalana d'ajuda al malalt de càncer, Girona).

\section{REFERENCES}

1. Soberanes S, Misharin AV, Jairaman A, MoralesNebreda L, McQuattie-Pimentel AC, Cho T, Hamanaka RB, Meliton AY, Reyfman PA, Walter JM, Chen Cl, Chi $M$, Chiu S, et al. Metformin Targets Mitochondrial Electron Transport to Reduce Air-Pollution-Induced Thrombosis. Cell Metab. 2019; 29:335-347.e5. https://doi.org/10.1016/i.cmet.2018.09.019 PMID:30318339

2. Channappanavar R, Fehr AR, Vijay R, Mack M, Zhao J, Meyerholz DK, Perlman S. Dysregulated type I interferon and inflammatory monocyte-macrophage responses cause lethal pneumonia in SARS-CoVinfected mice. Cell Host Microbe. 2016; 19:181-93. https://doi.org/10.1016/j.chom.2016.01.007 PMID:26867177

3. Kindler E, Thiel V. SARS-CoV and IFN: too little, too late. Cell Host Microbe. 2016; 19:139-41. 
https://doi.org/10.1016/j.chom.2016.01.012 PMID:26867172

4. Chen $G$, Wu D, Guo W, Cao Y, Huang $D$, Wang $H$, Wang $T$, Zhang $X$, Chen $H, Y u H$, Zhang $X$, Zhang $M$, Wu S, et al. Clinical and immunological features of severe and moderate coronavirus disease 2019. J Clin Invest. 2020; 130:2620-29.

https://doi.org/10.1172/JCl137244

PMID:32217835

5. Pedersen SF, Ho YC. SARS-CoV-2: a storm is raging. J Clin Invest. 2020; 130:2202-05. https://doi.org/10.1172/JCl137647 PMID:32217834

6. Klok FA, Kruip MJHA, van der Meer NJM, Arbous MS, Gommers DAMPJ, Kant KM, Kaptein FHJ, van Paassen J, Stals MAM, Huisman MV, Endeman H. Incidence of thrombotic complications in critically ill ICU patients with COVID-19. Thromb Res. 2020. [Epub ahead of print].

https://doi.org/10.1016/j.thromres.2020.04.013

PMID:32291094

7. Yang $\mathrm{Y}$, Tang H. Aberrant coagulation causes a hyperinflammatory response in severe influenza pneumonia. Cell Mol Immunol. 2016; 13:432-42. https://doi.org/10.1038/cmi.2016.1 PMID:27041635

8. Beristain-Covarrubias N, Perez-Toledo $M$, Thomas MR, Henderson IR, Watson SP, Cunningham AF. Understanding infection-induced thrombosis: lessons learned from animal models. Front Immunol. 2019; 10:2569.

https://doi.org/10.3389/fimmu.2019.02569

PMID:31749809

9. Wu X, Nethery RC, Sabath BM, Braun D, Dominici F. Exposure to air pollution and COVID-19 mortality in the United States. medRxiv. 2020.

https://doi.org/10.1101/2020.04.05.20054502

10. Conticini E, Frediani B, Caro D. Can atmospheric pollution be considered a co-factor in extremely high level of SARS-CoV-2 lethality in northern Italy? Environ Pollut. 2020; 261:114465.

https://doi.org/10.1016/j.envpol.2020.114465

PMID: 32268945

11. Martelletti L, Martelletti P. Air Pollution and the Novel Covid-19 Disease: a Putative Disease Risk Factor. SN Compr Clin Med. 2020; 1-5. [Epub ahead of print]. https://doi.org/10.1007/s42399-020-00274-4 PMID: $\underline{32296757}$

12. Ogen $\mathrm{Y}$. Assessing nitrogen dioxide $\left(\mathrm{NO}_{2}\right)$ levels as a contributing factor to coronavirus (COVID-19) fatality. Sci Total Environ. 2020; 726:138605. https://doi.org/10.1016/i.scitotenv.2020.138605 PMID:32302812
13. Ishii H, Fujii T, Hogg JC, Hayashi $S$, Mukae H, Vincent R, van Eeden SF. Contribution of IL-1 beta and TNF-alpha to the initiation of the peripheral lung response to atmospheric particulates (PM10). Am J Physiol Lung Cell Mol Physiol. 2004; 287:L176-83.

https://doi.org/10.1152/ajplung.00290.2003 PMID: 15003925

14. Pope CA 3rd, Bhatnagar A, McCracken JP, Abplanalp W, Conklin DJ, O'Toole T. Exposure to fine particulate air pollution is associated with endothelial injury and systemic inflammation. Circ Res. 2016; 119:1204-14. https://doi.org/10.1161/CIRCRESAHA.116.309279 PMID:27780829

15. Longhin E, Holme JA, Gualtieri M, Camatini M, Øvrevik J. Milan winter fine particulate matter (wPM2.5) induces IL-6 and IL-8 synthesis in human bronchial BEAS-2B cells, but specifically impairs IL-8 release. Toxicol In Vitro. 2018; 52:365-73.

https://doi.org/10.1016/j.tiv.2018.07.016 PMID:30048734

16. Tsai DH, Riediker M, Berchet A, Paccaud F, Waeber G, Vollenweider $\mathrm{P}$, Bochud $\mathrm{M}$. Effects of short- and longterm exposures to particulate matter on inflammatory marker levels in the general population. Environ Sci Pollut Res Int. 2019; 26:19697-704.

https://doi.org/10.1007/s11356-019-05194-y PMID:31079306

17. Li H, Cai J, Chen R, Zhao Z, Ying Z, Wang L, Chen J, Hao K, Kinney PL, Chen H, Kan H. Particulate matter exposure and stress hormone levels: a randomized, double-blind, crossover trial of air purification. Circulation. 2017; 136:618-27.

https://doi.org/10.1161/CIRCULATIONAHA.116.026796 PMID:28808144

18. Murray MA, Chotirmall SH. The impact of immunosenescence on pulmonary disease. Mediators Inflamm. 2015; 2015:692546.

https://doi.org/10.1155/2015/692546

PMID:26199462

19. Kovacs EJ, Boe DM, Boule LA, Curtis BJ. Inflammaging and the lung. Clin Geriatr Med. 2017; 33:459-71. https://doi.org/10.1016/j.cger.2017.06.002 PMID:28991644

20. Morty RE, Prakash YS. Senescence in the lung: is this getting old? Am J Physiol Lung Cell Mol Physiol. 2019; 316:L822-25.

https://doi.org/10.1152/ajplung.00081.2019 PMID:30892079

21. Parikh P, Wicher S, Khandalavala K, Pabelick CM, Britt RD Jr, Prakash YS. Cellular senescence in the lung across the age spectrum. Am J Physiol Lung Cell Mol Physiol. 2019; 316:L826-42. 
https://doi.org/10.1152/ajplung.00424.2018

PMID:30785345

22. Sargiacomo C, Sotgia F, Lisanti MP. COVID-19 and chronological aging: senolytics and other anti-aging drugs for the treatment or prevention of corona virus infection? Aging (Albany NY). 2020; 12:6511-17. https://doi.org/10.18632/aging.103001 PMID: 32229706

23. Strickland M, Yacoubi-Loueslati B, Bouhaouala-Zahar B, Pender SL, Larbi A. Relationships between ion channels, mitochondrial functions and inflammation in human aging. Front Physiol. 2019; 10:158. https://doi.org/10.3389/fphys.2019.00158 PMID:30881309

24. Stauderman KA. CRAC channels as targets for drug discovery and development. Cell Calcium. 2018; 74:147-59.

https://doi.org/10.1016/i.ceca.2018.07.005

PMID: 30075400

25. Yu LL, Zhu M, Huang Y, Zhao YM, Wen JJ, Yang XJ, Wu P. Metformin relieves acute respiratory distress syndrome by reducing miR-138 expression. Eur Rev Med Pharmacol Sci. 2018; 22:5355-63.

https://doi.org/10.26355/eurrev 201808 15737 PMID:30178862

26. Verdura $S$, Cuyàs $E$, Martin-Castillo $B$, Menendez JA. Metformin as an archetype immuno-metabolic adjuvant for cancer immunotherapy. Oncoimmunology. 2019; 8:e1633235.

https://doi.org/10.1080/2162402X.2019.1633235

PMID:31646077

27. Pålsson-McDermott EM, O'Neill LA. Targeting immunometabolism as an anti-inflammatory strategy. Cell Res. 2020; 30:300-14.

https://doi.org/10.1038/s41422-020-0291-z PMID:32132672

28. Qin C, Zhou L, Hu Z, Zhang S, Yang S, Tao Y, Xie C, Ma K, Shang K, Wang W, Tian DS. Dysregulation of immune response in patients with COVID-19 in Wuhan, China. Clin Infect Dis. 2020; ciaa248. [Epub ahead of print]. https://doi.org/10.1093/cid/ciaa248

PMID: 32161940

29. Stebbing J, Phelan A, Griffin I, Tucker C, Oechsle O, Smith D, Richardson P. COVID-19: combining antiviral and anti-inflammatory treatments. Lancet Infect Dis. 2020; 20:400-02. https://doi.org/10.1016/S1473-3099(20)30132-8 PMID:32113509
30. Zhavoronkov A. Geroprotective and senoremediative strategies to reduce the comorbidity, infection rates, severity, and lethality in gerophilic and gerolavic infections. Aging (Albany NY). 2020; 12:6492-510.

https://doi.org/10.18632/aging.102988

PMID:32229705

31. Barzilai N, Crandall JP, Kritchevsky SB, Espeland MA. Metformin as a tool to target aging. Cell Metab. 2016; 23:1060-65.

https://doi.org/10.1016/j.cmet.2016.05.011 PMID:27304507

32. Newman JC, Milman S, Hashmi SK, Austad SN, Kirkland $\mathrm{JL}$, Halter JB, Barzilai N. Strategies and challenges in clinical trials targeting human aging. J Gerontol A Biol Sci Med Sci. 2016; 71:1424-34.

https://doi.org/10.1093/gerona/glw149 PMID:27535968

33. Kulkarni AS, Gubbi S, Barzilai N. Benefits of Metformin in Attenuating the Hallmarks of Aging. Cell Metab. 2020. [Epub ahead of print]. https://doi.org/10.1016/j.cmet.2020.04.001 PMID:32333835

34. Waldron RT, Chen Y, Pham H, Go A, Su HY, Hu C, Wen L, Husain SZ, Sugar CA, Roos J, Ramos S, Lugea A, Dunn $M$, et al. The orai $\mathrm{ca}^{2+}$ channel inhibitor CM4620 targets both parenchymal and immune cells to reduce inflammation in experimental acute pancreatitis. J Physiol. 2019; 597:3085-105. https://doi.org/10.1113/JP277856 PMID:31050811

35. Zhou F, Yu T, Du R, Fan G, Liu Y, Liu Z, Xiang J, Wang Y, Song B, Gu X, Guan L, Wei Y, Li H, et al. Clinical course and risk factors for mortality of adult inpatients with COVID-19 in wuhan, China: a retrospective cohort study. Lancet. 2020; 395:1054-62. https://doi.org/10.1016/S0140-6736(20)30566-3 PMID: 32171076

36. Gattinoni L, Coppola S, Cressoni M, Busana M, Rossi S, Chiumello D. COVID-19 does not lead to a "typical" acute respiratory distress syndrome. Am J Respir Crit Care Med. 2020; 201:1299-300. https://doi.org/10.1164/rccm.202003-0817LE PMID:32228035

37. Magro C, Mulvey JJ, Berlin D, Nuovo G, Salvatore S, Harp J, Baxter-Stoltzfus A, Laurence J. Complement associated microvascular injury and thrombosis in the pathogenesis of severe COVID-19 infection: a report of five cases. Transl Res. 2020. [Epub ahead of print]. https://doi.org/10.1016/i.trsl.2020.04.007 PMID:32299776 